\title{
Vitamin A and public health: challenges for the next decade
}

\author{
David A. Ross* \\ Department of Infectious and Tropical Diseases, London School of Hygiene and Tropical Medicine, Keppel Street, \\ London WC1E 7HT, UK
}

Since 1980 , there has been a revolution in our understanding of the major role which vitamin A plays in mortality and morbidity from infectious diseases. In the present paper, the results of the epidemiological studies which have led to this revolution are reviewed, and used as the basis to set challenges for the next decade.

\section{Vitamin A deficiency and mortality and morbidity in older infants ( $\geq 6$ months) and young children}

A series of large, community-based, randomized controlled trials have shown that improving the vitamin A intake of children in populations in which vitamin A deficiency is prevalent substantially reduces their risk of death (Sommer et al. 1986; Muhilal et al. 1988; Rahmathullah et al. 1990; Vijayaraghavan et al. 1990; West et al. 1991; Daulaire et al. 1992; Herrera et al. 1992; Ghana VAST Study Team, 1993; Table 1). A meta-analysis of these eight trials concluded that, in similar populations to those in which the trials were conducted, one could reasonably expect a reduction in mortality of children aged 6 months -5 years of between 1 and 40 (mean 23)\%, if similar levels of intervention coverage were achieved (Beaton et al. 1993).

Most (Sommer et al. 1986; Rahmathullah et al. 1990; Vijayaraghavan et al. 1990; West et al. 1991; Daulaire et al. 1992), but not all (Ghana VAST Study Team, 1993), of the trials which found a significant impact on mortality

Table 1. Results of eight major trials of the impact of prophylactic vitamin A on child mortality (Data from Beaton et al. 1993)

\begin{tabular}{lcl}
\hline & \multicolumn{2}{c}{ Rate ratio, vitamin A : placebo } \\
\cline { 2 - 3 } Study & Mean & $95 \% \mathrm{Cl}$ \\
\hline Indonesia: Aceh & 0.73 & $0.56-0.95$ \\
MSG & 0.70 & $0.58-0.85$ \\
India: Tamil Nadu & 0.46 & $0.31-0.67$ \\
Hyderabad & 0.94 & $0.61-1.46$ \\
Nepal: Sarlahi Child & 0.70 & $0.57-0.86$ \\
Jumla & 0.74 & $0.60-0.91$ \\
Sudan & 1.06 & $0.82-1.37^{\mathrm{NS}}$ \\
Ghana: VAST Survival & 0.81 & $0.68-0.98$ \\
Overall estimate & 0.77 & $0.71-0.84$ \\
\hline
\end{tabular}

suggested sex-specific differences in the effect of vitamin A supplementation, but the direction of these differences was not consistent. A meta-analysis of all eight trials showed no significant difference by sex, or by age (Beaton et al. 1993). However, there do appear to be important differences in the impact of vitamin A on different causes of death. Metaanalyses of data from those trials which collected cause of death information, showed that there was a substantial impact on diarrhoea-related deaths (Beaton et al. 1993), but no significant impact on acute lower respiratory tract infection-related deaths (Vitamin A and Pneumonia Working Group, 1995). Only the study in Ghana had a substantial number of deaths thought to be due to malaria, but there was no suggestion of an impact on either malariarelated deaths or morbidity in this trial (Binka et al. 1995).

Improving children's vitamin A intake may also reduce their risk of severe morbidity (Arthur et al. 1992; Ghana VAST Study Team, 1993; Barreto et al. 1994), although the results from trials of the impact of vitamin A supplementation on the incidence, prevalence, severity or duration of morbidity have been less consistent than those for mortality (Beaton et al. 1993). Furthermore, clinical trials of vitamin A supplementation of African children with severe measles have demonstrated significantly decreased mortality (Barclay et al. 1987; Hussey \& Klein, 1990) and morbidity (Hussey \& Klein, 1990; Coutsoudis et al. 1991). Even though similar clinical trials in children with less-severe measles (Rosales et al. 1996), diarrhoea (Henning et al. 1992; Bhandari et al. 1994), and pneumonia (Kjolhede et al. 1995; L Nacul, personal communication) have failed to show clear-cut, short-term beneficial effects, the overall mortality-sparing effects of vitamin A are now beyond dispute (Beaton et al. 1993).

One of the major challenges to all public health and nutrition programmes in developing countries in the next decade will be to turn this new knowledge into effective, large-scale intervention programmes in vitamin A-deficient populations. There are three major approaches to achieve this: supplementation; food fortification; food-based dietary interventions. The best choice of approach or combination of approaches, and the specific strategies which should be employed (e.g. fortification of a staple food or a food additive) will require careful study in each setting. There is

\footnotetext{
* Present address: AMREF, PO Box 1482, Mwanza, Tanzania.

Corresponding author: Dr D. A. Ross, fax +25568500742, email dross@tan2.healthnet.org
} 
no universal best solution, and the choice should be based on an assessment not only of technical issues, but also of socio-cultural and political issues. However, such assessments must be carried out quickly so that effective programmes can be initiated without delay, because it has been shown that improving the vitamin A status of a very high proportion of the young children in the developing countries can be one of the most cost-effective interventions available to public health (Levin et al. 1993; World Bank, 1993).

Over the past 15 years, nutritional interventions have not been given a high priority by many governments and international donors. The clear evidence that improving the vitamin A status of young children can have such a major impact on their survival should be enough to reverse this neglect over the next decade. The demonstration that mild and moderate growth deficit is also associated with a substantial proportion of child mortality in developing countries (Pelletier, 1994), and the evidence that other micronutrient deficiencies, including $\mathrm{Fe}, \mathrm{I}$, and $\mathrm{Zn}$, are also underlying causes of both morbidity and mortality in poor children (Levin et al. 1993; Sazawal et al. 1996), means that nutritionists have all the evidence they need to insist that nutritional interventions are integrated into health programmes in all developing countries. It should not be added as a token afterthought, but as a fundamental priority, alongside immunization and management of diarrhoea, acute lower respiratory tract infections, and malaria. Over the next decade, this unique opportunity to greatly improve the health, development, and survival of future generations of young children in developing countries must not be missed.

\section{The safety and efficacy of vitamin A supplementation in early infancy}

A current research challenge is the elucidation of whether similar benefits to those in older infants and young children should be expected from vitamin A supplementation in early infancy (i.e. aged less than 6 months). Three randomized controlled trials have examined the impact of vitamin A supplementation of young infants on their subsequent mortality and morbidity; two trials were conducted in Nepal (Daulaire et al. 1992; West et al. 1995), and one trial in Indonesia (Humphrey et al. 1996). The two trials in Nepal were community-based trials in which high doses of vitamin A were given to all children aged less than 6 months. Neither trial found a significant impact on mortality. The trial in Indonesia included all infants born within a large hospital in Bandung, who were either given a $15 \mathrm{mg}$ dose of vitamin $\mathrm{A}$ or a placebo within $12 \mathrm{~h}$ of birth (Humphrey et al. 1996). The infants were then followed-up at home until they were 12 months old. The mortality rate was $64 \%$ lower in the vitamin A group $(P<0.01)$. The mortality reduction appeared to be confined to the post-neonatal period when infectious diseases are more prevalent.

An alternative approach to supplementing the vitamin A intake of breast-fed infants is via their mothers' breast milk. Unfortunately, high doses of vitamin A can be teratogenic, especially when given early in pregnancy; therefore, they are not recommended in women, except within 6 weeks after delivery (International Vitamin A Consultative Group, 1986). A randomized controlled trial in Indonesia showed that a single $90 \mathrm{mg}$ dose of vitamin A to mothers significantly increased the serum retinol concentration of their infants for at least their first 8 months of life (Stoltzfus et al. 1993). A placebo-controlled trial in Matlab, Bangladesh, went on to test the impact on infant mortality during the first 6 months after the dose (de Francisco et al. 1994). Despite including a total of 8735 infants, the trial was still too small to be able to detect all but a very substantial impact on mortality in the infants. Although the mortality was $18 \%$ lower in the infants whose mothers were supplemented, this difference was not statistically significant $(95 \%$ CI $0.58,1 \cdot 14)$. On the other hand, both suspected acute lower respiratory tract infection (i.e. cough plus measured rapid breathing; rate ratio $1.44,95 \% \mathrm{CI}$ $1 \cdot 10,1.87$ ) and reported diarrhoea (rate ratio $1.56,95 \% \mathrm{CI}$ $1.29,1.89$ ) were substantially and significantly increased in the infants whose mothers had been allocated vitamin $\mathrm{A}$.

In summary, with the notable exception of the trial in Bandung, Indonesia, the results of these trials of improvements in the vitamin A intake of young infants (either directly or via their mothers' breast milk) have tended to be disappointing compared with those in older infants and young children. Although this may have been related to the results having insufficient power to give a definitive answer, a clear-cut answer as to whether vitamin A supplementation in early infancy is safe and efficacious is important for two main reasons. First, mortality and morbidity rates are highest in this age-group; therefore, any beneficial effect will be particularly important. Second, a high proportion of young infants have several contacts with health services during infancy, often receiving an immunization at these contacts. The potential exists, therefore, for reaching these infants at very low marginal cost. At least three relevant trials (in Ghana, India, and Peru) are due to complete their data collection during 1997. These placebo-controlled trials are evaluating the impact of vitamin $A$ on the incidence of immediate potential side effects, vitamin A status, and the incidence, duration and severity of morbidity in infants up to the age of 9 months ( $P$ Arthur, personal communication). These trials should greatly improve our understanding of the safety and efficacy of vitamin A supplementation in early infancy, although they may not have the power to detect important impacts on mortality, and none of the three study sites is in a population with a high prevalence of xerophthalmia.

These trials will also provide important data on whether high-dose vitamin A supplements cause functionally important side effects in this age-group when administered at the same time as routine infant immunizations. Concern about this possibility arose from trials in Matlab, Bangladesh, which found an increased incidence of bulging fontanelle in young infants given either $15 \mathrm{mg}$ (de Francisco et al. 1993) or $7.5 \mathrm{mg}$ (Baqui et al. 1994) vitamin A with each dose of diphtheria-pneumonia-tetanus and poliomyelitis vaccine at approximately 6,10 and 14 weeks of age. The increase in transient bulging fontanelle was confirmed in trials in Nepal (West et al. 1992, 1995) 
and in Indonesia (Humphrey et al. 1996). However, the functional significance of transient bulging fontanelle has been questioned, especially as it appears to be due to a transient increase in cerebrospinal volume in the absence of increased cerebrospinal pressure (Humphrey et al. 1996). Further data will come from the trials in Ghana, India, and Peru mentioned previously, and from developmental follow-up of the infants involved in the Bandung trial ( $\mathrm{J}$ Humphrey, personal communication).

Further worries about potential side effects of vitamin A given at the same time as infant vaccines came from the results of a placebo-controlled trial in Indonesia of the effect of a single $30 \mathrm{mg}$ dose of vitamin A given at the same time as measles vaccine when the infant was aged 6 months (Semba et al. 1995). Although, overall, there was no significant difference in the immune response to the vaccine, a subgroup analysis showed that the response was lower in those infants who still had substantial concentrations of maternal measles antibody. Arguments that this was less likely to occur when the vaccine was given at the more usual age of 9 months and above (Ross, 1995) have been borne out by the results of a recent trial in infants in Guinea-Bissau (Benn et al. 1997). In fact, there was a suggestion from this trial that the vaccine response at this age may have been increased by concurrent vitamin A supplementation in boys.

It seems likely, therefore, that it will become possible to give clear-cut recommendations about vitamin A supplementation of young infants (either direct or via the mother's breast milk) within the next year or so. In the meantime, it is safest to restrict this to $30 \mathrm{mg}$ for infants aged 6 months or more, with a minimum interval of 4 months between doses. Fortunately, it now appears to be safe to give a dose at the same time as measles vaccine, when this is administered at the usual age of 9 months and above.

\section{The safety and efficacy, in both mother and infant, of vitamin A supplementation in pregnancy}

Studies in Asia have shown that vitamin A deficiency can be common in both pregnant and lactating women (Dixit, 1966; Mandal et al. 1969; Bloem et al. 1995; Katz et al. 1995). However, until very recently, attention has focused on the dangers of high doses of vitamin $A$ to the fetus (International Vitamin A Consultative Group, 1986), and the restrictions this imposes on supplementation, or even consumption of vitamin A-rich foods such as liver, during pregnancy (Hathcock et al. 1990; Sommer \& West, 1996). On the other hand, vitamin A deficiency has also been shown to adversely affect embryogenesis (Olson, 1972, 1996; Hofman \& Eichele, 1994). Improving the vitamin A intake of deficient pregnant women, therefore, may have benefits both to the woman herself and to her fetus and the young infant. The efficacy of frequent low-dose vitamin A supplements administered to pregnant women is currently being tested within a large-scale community-based trial in Nepal (KP West, personal communication). The results of this trial will be crucial in guiding policy and programmes. If they show a clear benefit to the woman, her fetus or young infant, they will challenge health and nutrition services to devise feasible and sustainable interventions to improve the vitamin A intake of pregnant women, while avoiding the potential risks of toxicity to the fetus.

\section{Vitamin $A$ and human immunodeficiency virus infection}

Recent studies in adults in developed countries (mainly in the USA) have demonstrated a consistent association between human immunodeficiency virus (HIV)-acquired immune deficiency syndrome (AIDS) and vitamin A deficiency (Bogden et al 1990; Calle et al. 1991; Baum et al. 1992; Beach et al. 1992; Semba et al. 1993; Ward et al. 1993; Ward \& Semba, 1994). A cohort study in 126 HIV-1 seropositive and fifty-three HIV-1 seronegative adult intravenous-drug users in Baltimore, MD, showed that mortality over a mean follow-up period of 22.8 months was significantly higher in the HIV-1 seropositive adults whose initial serum retinol concentration was $<1.05 \mu \mathrm{mol} / \mathrm{l}$ relative to those whose serum retinol concentration was $\geq 1.05 \mu \mathrm{mol} / 1$ (relative risk $4.3(95 \%$ CI 1.1, 17.8 after adjusting for a wide range of potential confounders; Semba et al. 1993).

In another cohort study in Baltimore and Washington, DC, HIV-1 seropositive homosexual and/or bisexual men whose total dietary vitamin A intake was two to four times the recommended dietary allowance had substantially lower rates of progression to symptomatic AIDS, both in comparison with men whose intake was lower and higher than this (Tang et al. 1993). The number of men who had intakes likely to lead to deficiency was too small to allow the impact of vitamin A deficiency on disease progression to be examined.

The same cohort of HIV-1 seropositive homosexual and/ or bisexual men has been used to examine the association between serum retinol concentration at enrolment and risk of progression to AIDS over a 9-year period. No significant association was found in this cohort, but serum retinol concentrations were uniformly in the normal to high range (median $2.44 \mu \mathrm{mol} / 1$; Tang et al. 1997).

Unfortunately, none of the studies to date have measured acute-phase proteins, or adequately adjusted for the effects of concurrent infections on the measurements of serum retinol concentration. However, they indicate that vitamin A status may be associated with the progression of HIV-1 infection in adults, at least in some populations.

Additional indications that retinoids may be important in HIV-AIDS come from clinical reports that several of the conditions which are frequent complications in HIVpositive individuals (psoriasis, Reiter's syndrome, Kaposi's sarcoma, lichen planus, papillomavirus infection, and oral hairy leukoplakia) respond to retinoid supplements (Ward \& Semba, 1994).

This evidence from multiple sources has led some workers to suggest that vitamin A and the retinoids may have a potential role in the treatment of HIV infection (Poli et al. 1992). However, in vitro studies have shown conflicting results. Several studies have indicated that retinoic acid and other retinoids can significantly increase HIV replication (Yamamoto et al. 1986; Kitano et al. 1990; Poli et al. 1992; Poli \& Fauci, 1992; Turpin et al. 1992) or 
Table 2. Relative and attributable risks of vertical transmission of human immunodeficiency virus infection according to maternal serum retinol concentration during pregnancy in Malawi (Data from Semba et al. 1994)

\begin{tabular}{lccccc}
\hline \multirow{2}{*}{$\begin{array}{l}\text { Serum retinol concentration } \\
\text { of mother during pregnancy } \\
(\mu \mathrm{mol} / \mathrm{l})\end{array}$} & \multicolumn{2}{c}{$\begin{array}{c}\text { Relative risk of vertical } \\
\text { transmission }\end{array}$} & & \multicolumn{2}{c}{$\begin{array}{c}\text { Attributable risk of } \\
\text { vertical transmission }\end{array}$} \\
\cline { 2 - 3 } & Mean & $(95 \% \mathrm{Cl})$ & & Mean & $(95 \% \mathrm{Cl})$ \\
\hline$<0.70$ & 4.4 & $(+1.6,+12.0)$ & & 0.25 & $(+0.12,+0.37)$ \\
$0.70-1.05$ & 3.6 & $(+1.3,+9.6)$ & & 0.19 & $(+0.09,+0.29)$ \\
$1.05-1.40$ & 2.2 & $(+0.8,+6.3)$ & & 0.09 & $(-0.01,+0.19)$ \\
$\geq 1.40$ & 1.0 & & & 0.00 & \\
\hline
\end{tabular}

enhance transcription from the HIV-1 long terminal repeat (Collins, 1988; Maio \& Brown, 1988) in human monocytes and monocyte-like cells, and Poli et al. (1992) have reported that retinoids can also block HIV expression in infected monocytes. Ultimate answers, as to whether or not vitamin A status is related either to HIV incidence or to the progression of HIV disease if an individual is infected, will have to come from community-based and clinical trials respectively. The former will need large sample sizes.

A cohort study in $338 \mathrm{HIV}$-1-infected pregnant women in Malawi showed a strong inverse correlation between the maternal serum retinol concentration during pregnancy and vertical transmission of HIV infection to the infant (Semba et al. 1994; Table 2). This was assessed in women whose infant survived to 12 months of age, and whose infant's HIV serostatus at that age was known. The odds ratio of vertical transmission was $0.56(95 \%$ CI $0.37,0.85)$ for each $0.45 \mu \mathrm{mol} / \mathrm{l}$ increase in serum retinol, after controlling for maternal age, BMI, and CD4 cell count (Semba et al. 1994). The mean serum retinol concentration during pregnancy of HIV-1-infected mothers whose infants died before they reached 12 months $(0.78$ (SE 0.3$) \mu \mathrm{mol} / \mathrm{l})$ was similar to that of the mothers whose infants survived to 12 months but were HIV- 1 seropositive at that age $(0.86$ (SE $0.03) \mu \mathrm{mol} / \mathrm{l}$ ), but was lower than that of mothers whose infants survived to 12 months and were HIV-1 seronegative at that age $(1.07$ (SE 0.02$) \mu \mathrm{mol} / \mathrm{l} ; P<0.0001)$. Several trials of the impact on vertical transmission of HIV infection of low-dose vitamin A supplements given to HIV-1-infected pregnant women are currently underway in Africa (RD Semba, personal communication). If these report positive results, this will provide one of very few interventions for the prevention of HIV infection.

\section{The importance of vitamin A deficiency in older children and adolescents}

Vitamin A deficiency frequently extends into later childhood, adolescence, and even into adulthood in affected developing country populations (Sommer \& West, 1996). In fact, the prevalence of mild forms of xerophthalmia (night-blindness and/or Bitot's spot) has usually been found to be higher among school-age children than among younger children in Asia (Solon et al. 1978; Khan et al. 1984; Brilliant et al. 1985; Upadhyay et al. 1985; Hennig et al. 1991; Gopaldas, 1992). This is in contrast to the more severe, potentially-blinding corneal xerophthalmia which is rare after the sixth birthday (Sommer \& West, 1996). Two large hospital series in Asia have found that less than $10 \%$ of cases of active corneal xerophthalmia were in children aged 6 years or more (Sommer, 1982; Hennig et al. 1991).

Very few studies have been conducted among older children or adolescents on the importance of vitamin A deficiency, or the potential of vitamin A supplementation. This has been mainly because until recently the focus of attention in relation to vitamin A deficiency was on blinding xerophthalmia, and because absolute mortality (and most morbidity) rates decline with age from infancy through childhood and into adolescence. However, a small placebo-controlled trial in schoolboys aged 7-15 years attending a school for slum children in Baroda, India, found that high doses of vitamin A given twice at 6-month intervals substantially reduced both the prevalence of xerophthalmia, and the proportion of children with severe or moderate biochemical deficiency (Pant \& Gopaldas, 1987). A subsequent placebo-controlled trial in 210 schoolboys (aged 9-15 years) attending four primary schools in the same city has reported that children receiving $60 \mathrm{mg}$ vitamin $\mathrm{A}$ on three occasions at 4-month intervals had a significantly lower prevalence, incidence and duration of several common childhood morbidities, although surprisingly not for diarrhoea (Bakshi \& Gopaldas, 1990). Unfortunately, this trial has only been reported as an abstract, and details of the study design, its execution and results are not available.

One of the recent trials of the impact of vitamin A supplementation on mortality in young children included children aged 6-7 years (Ghana VAST Study Team, 1993). In this large trial in northern Ghana, there was no evidence of a trend by age in the impact on mortality of high-dose vitamin A supplements given every 4 months; in fact, the impact among children aged 72-95 months (a 61\% mortality reduction) was higher (although not significantly higher) than that in any other age group (Ghana VAST Study Team, 1993). It is possible, therefore, that the reductions in mortality associated with vitamin A supplementation may persist throughout childhood and beyond, and be coupled to substantial reductions in severe morbidity from infectious diseases, especially from diarrhoea. Intervention studies are urgently needed to confirm or refute this hypothesis, and to provide guidance for school health programmes, in which there is uncertainty about whether or not to include vitamin A supplementation in their package of interventions. 


\section{The potential of dietary interventions to improve vitamin A status}

Recent work has thrown into question previous assumptions related to the bioavailability of vitamin A precursors in vegetable foods (de Pee et al. 1995), and their retention in processed and stored foods (Rodriguez-Amaya, 1997). It may well be that the bioavailability of vitamin A from vegetable sources is much lower than had been thought previously. Studies are now underway to investigate this possibility (CE West, personal communication), but such studies are often difficult to design and interpret. The reasons for this are: the enormous variety of vegetables and fruits which exists; the different vitamin A content of local strains of each species, and of the same strain at different stages of maturity; the variable losses through storage, processing and cooking; and the impact on carotenoid bioavailability of other foodstuffs (e.g. oil, phytates) which are eaten at the same time. At the population level, there have been very few studies of the impact of dietary-based interventions on vitamin A status. Such studies are urgently needed to complement the bioavailability studies mentioned previously.

\section{Conclusions}

The present review has highlighted seven major challenges which face those of us working in public health and nutrition in developing countries over the next decade:

1. the implementation of effective and sustainable, largescale interventions to prevent the substantial burden of mortality and severe morbidity which is attributable to vitamin A deficiency in older infants and young children;

2. further studies of the safety and efficacy of vitamin A supplementation in early infancy, and incorporation of appropriate vitamin A interventions targeted at young infants into maternal and child health care programmes, if the results are positive. This may include incorporating vitamin A supplementation into the standard postnatal care of both mothers and neonates and/or administering vitamin A supplements alongside early infant immunizations such as Bacillus CalmetteGuérin, poliomyelitis, and diphtheria-pneumoniatetanus;

3. studies of the safety and efficacy, in both mother and infant, of vitamin A supplementation in pregnancy, and incorporation of appropriate vitamin A interventions into maternal health programmes, if the results are positive;

4. randomized controlled field trials of the impact of vitamin A supplementation on the transmission and progression of HIV;

5. the completion of a series of current trials of the impact of low-dose vitamin A supplementation on vertical transmission of HIV, and incorporation of vitamin A supplementation into the standard care of HIV-infected pregnant women, if the results of the trials justify this;

6. investigation of the functional importance of vitamin A deficiency in older children and adolescents, and the design and implementation of suitable interventions for both school-going and non-school-going children;

7. studies of the bioavailability of vitamin A precursors in vegetable foods, and of the potential of dietary interventions to improve the vitamin A status of populations.

This list is by no means exhaustive. Further, unexpected challenges will come to light over the next decade, based on the results of the large volume of innovative research which is currently in progress or planned. The international nutrition community must rise to these challenges. Never before have we been armed with such compelling evidence that nutritional interventions have the potential to make a huge impact on the survival and health of poor populations. The greatest challenge of the next decade will be to ensure that this evidence is translated into effective action and, thereby, into a substantial reduction in the burden of illhealth and mortality in vitamin A-deficient populations throughout the developing world.

\section{References}

Arthur P, Kirkwood B, Ross D, Morris S, Gyapong J, Tomkins A \& Addy H (1992) Impact of vitamin A supplementation on childhood morbidity in northern Ghana. Lancet 339, 361-362.

Bakshi M \& Gopaldas T (1990) Impact of mega vitamin A dosing on the morbidity profile of under-privileged school boys (9-15 yrs). In National Symposium and XIII IVACG Meeting Report, Kathmandu, Nepal, p. 87. Washington, DC: IVACG.

Baqui AH, de Francisco A, Arifeen SE, Siddique AK \& Sack RB (1994) Bulging fontanelle after supplementation with $25,000 \mathrm{IU}$ vitamin A in infancy using EPI contacts. In Vitamin A Symposium, Programme and Abstracts, p. 7. Dhaka, Bangladesh: ICDDR.

Barclay AJG, Foster A \& Sommer A (1987) Vitamin A supplements and mortality related to measles: a randomised clinical trial. British Medical Journal 294, 294-296.

Barreto ML, Santos LMP, Assis AMO, Araujo MPN, Farenzena GG, Santos PAB \& Fianconne RL (1994) Effect of vitamin A supplementation on diarrhoea and acute lower-respiratory-tract infections in young children in Brazil. Lancet 344, 228-231.

Baum MK, Shor-Posner G, Bonveni P, Cassetti I, ManteroAtienza E, Beach RS \& Sauberlich HE (1992) Influence of HIV infection on vitamin A status and requirements. Annals of the New York Academy of Sciences 669, 165-173.

Beach RS, Mantero-Atienza E, Shor-Posner G, Javier JJ, Szapocznik J, Morgan R, Sauberlich HE, Cornwell PE, Eisdorfer C \& Baum MK (1992) Specific nutrient abnormalities in asymptomatic HIV-1 infection. AIDS 6, 701-708.

Beaton GH, Martorell R, L'Abbé KA, Edmonston B, McCabe G, Ross AC \& Harvey B (1993) Effectiveness of Vitamin A Supplementation in the Control of Young Child Morbidity and Mortality in Developing Countries. ACC/SCN State-of-the-art Series, Nutrition Policy Discussion Paper no. 13. Geneva: ACC/SCN.

Benn CS, Aaby P, Bale C, Olsen J, Michaelson KF, George E \& Whittle H (1997) Randomised trial of effect of vitamin A supplementation on the antibody response to measles vaccine in Guinea-Bissau, West Africa. Lancet 350, 101-105.

Bhandari N, Bhan MK \& Sazawal S (1994). Impact of massive dose of vitamin A given to preschool children with acute diarrhoea on subsequent respiratory and diarrhoeal morbidity. British Medical Journal 309, 1404-1407. 
Binka FN, Ross DA, Morris SS, Kirkwood BR, Arthur P, Dollimore N, Gyapong JO \& Smith PG (1995) Vitamin A supplementation and childhood malaria in northern Ghana. American Journal of Clinical Nutrition 61, 853-859.

Bloem MW, Matzger H \& Huq N (1995) Vitamin A deficiency among women in the reproductive years: an ignored problem. In Two Decades of Progress: Linking Knowledge to Action. Report of the XVI International Vitamin A Consultative Group Meeting, Chiang Rai, Thailand, p. 78. Washington, DC: IVACG.

Bogden JD, Baker H, Frank O, Perez G, Kemp F, Bruening K \& Louria D (1990) Micronutrient status and human immunodeficiency virus (HIV) infection. Annals of the New York Academy of Sciences 587, 189-195.

Brilliant LB, Pokhrel RP, Grasset NC, Lepkowski JM, Kolstad A, Hawks W, Pararajasegaram R, Brilliant GE, Gilbert S, Shrestha SR \& Kuo J (1985) Epidemiology of blindness in Nepal. Bulletin of the World Health Organization 63, 375-386.

Calle PF, Miguel MJG, Codoceo R, Gomez A, Mellado MJ, Fontelo PM \& de Jose MI (1991) Status of vitamin A and its carrier in pediatric population infected with HIV. VIIth International Conference on AIDS, 2508 Abstr.

Collins SJ (1988) Retinoic acid-induced differentiation of retrovirus-infected HL-60 cells is associated with enhanced transcription from the viral long terminal repeat. Journal of Virology 62, 4349-4352.

Coutsoudis A, Broughton M \& Coovadia HM (1991) Vitamin A supplementation reduces measles morbidity in young African children: a randomized, placebo-controlled, double-blind trial. American Journal of Clinical Nutrition 54, 890-895.

Daulaire NMP, Starbuck ES, Houston RM, Church MS, Stukel TA \& Pandey MR (1992) Childhood mortality after a high dose of vitamin A in a high risk population. British Medical Journal 304, 207-210.

de Francisco A, Chakraborty J, Chowdhury HR, Yunus M, Baqui AH, Siddique AK \& Sack RB (1993) Acute toxicity of vitamin A given with vaccines in infancy. Lancet 342, 526-527.

de Francisco A, Yasui Y \& Chakraborty J (1994) Vitamin A given to mothers after delivery reduces infant mortality and increases symptoms of morbidity. In Two Decades of Progress: Linking Knowledge to Action. Report of the XVI International Vitamin A Consultative Group Meeting, Chiang Rai, Thailand, p. 69. Washington, DC: IVAGC.

de Pee S, West CE, Muhilal, Karyadi D \& Hautvast JGAJ (1995) Lack of improvement in vitamin A status with increased consumption of dark-green leafy vegetables. Lancet 346, 7581.

Dixit DT (1966) Night-blindness in the third trimester of pregnancy. Indian Journal of Medical Research 54, 791-795.

Ghana VAST Study Team (1993) Vitamin A supplementation in northern Ghana: effects on clinic attendances, hospital admissions, and child mortality. Lancet 342, 7-12.

Gopaldas T (1992) Vitamin A deficiency beyond the preschool years. In Bellagio Meeting on Vitamin A Deficiency and Childhood Mortality, p. 56 [KP West Jr, editor]. New York: Helen Keller International.

Hathcock JN, Hattan DG, Jenkins MY, McDonald JT, Sundaresan PR \& Wilkenin VL (1990) Evaluation of vitamin A toxicity. American Journal of Clinical Nutrition 52, 183-202.

Hennig A, Foster A, Shrestha SP \& Pokhrel RP (1991) Vitamin A deficiency and corneal ulceration in south-east Nepal: implications for preventing blindness in children. Bulletin of the World Health Organization 69, 235-239.

Henning B, Stewart K, Zaman K, Alam AN, Brown KH \& Black RE (1992) Lack of therapeutic efficacy of vitamin A for noncholera, watery diarrhoea in Bangladeshi children. European Joumal of Clinical Nutrition 46, 437-443.
Herrera MG, Nestel P, El Amin A, Fawzi WW, Mohamed KA \& Weld L (1992) Vitamin A supplementation and child survival. Lancet 340, 267-271.

Hofman C \& Eichele G (1994) Retinoids in development. In The Retinoids: Biology, Chemistry and Medicine, 2nd ed., pp. 387441 [MB Sporn, AB Roberts and DS Goodman, editors]. New York: Raven Press.

Humphrey JH, Agoestina T, Wu L, Usman A, Nurachim M, Subardja D, Hidyat S, Tielsch J, West KP Jr \& Sommer A (1996) Impact of neonatal vitamin A supplementation on infant morbidity and mortality. Journal of Pediatrics 128, 489-496.

Hussey GD \& Klein M (1990) A randomized, controlled trial of vitamin A in children with severe measles. New England Journal of Medicine 323, 160-164.

International Vitamin A Consultative Group (1986) The Safe Use of Vitamin A by Women During the Reproductive Years. Washington, DC: IVACG.

Katz J, Khatry SK, West KP, Humphrey JH, Leclerq SC, Pradhan EK, Pohkrel RP \& Sommer A (1995) Night blindness is prevalent during pregnancy and lactation in rural Nepal. Journal of Nutrition 125, 2122-2127.

Khan MU, Haque E \& Khan MR (1984) Nutritional ocular diseases and their association with diarrhoea in Matlab, Bangladesh. British Journal of Nutrition 52, 1-9.

Kitano K, Baldwin GC, Raines MA \& Golde DW (1990) Differentiating agents facilitate infection of myeloid leukemia cell lines by monocytotropic HIV-1 strains. Blood 76, 19801988.

Kjolhede CL, Chew FJ, Gadomski AM \& Marroquin DP (1995) Clinical trial of vitamin A as adjuvant treatment for lower respiratory tract infections. Journal of Pediatrics 126, 807-812.

Levin HM, Pollitt E, Galloway R \& McGuire J (1993) Micronutrient deficiency disorders. In Disease Control Priorities in Developing Countries, pp. 421-454 [DT Jamison, WH Mosley, AR Measham and JL Bobadilla, editors]. New York: Oxford University Press \& World Bank.

Maio JJ \& Brown FL (1988) Regulation of expression driven by human immunodeficiency virus type 1 and human T-cell leukemia virus type 1 long terminal repeats in pluripotential human embryonic cells. Journal of Virology 62, 1398-1407.

Mandal GS, Nanda KN \& Bose J (1969) Night blindness in pregnancy. Journal of Obstetrics and Gynaecology of India 19, 453-458.

Muhilal, Permeisih D, Idjradinata YR, Muherdiyantiningsih \& Karyadi D (1988) Vitamin A fortified monosodium glutamate and health, growth, and survival of children: a controlled field trial. American Journal of Clinical Nutrition 48, 1271-1276.

Olson JA (1972) The biological role of vitamin A in maintaining epithelial tissues. Israel Journal of Medical Science 8, 11701178.

Olson JA (1996) Biochemistry of vitamin A and carotenoids. In Vitamin A Deficiency: Health, Survival, and Vision, pp. 221250 [A Sommer and KP West Jr, editors]. New York: Oxford University Press.

Pant I \& Gopaldas T (1987) Effect of mega doses of vitamin A on the vitamin A status of underprivileged school-age boys (7-15 yr). Indian Journal of Medical Research 86, 196-206.

Pelletier DL (1994) The relationship between child anthropometry and mortality in developing countries: implications for policy, programs and future research. Journal of Nutrition 124, Suppl., S2047-S2081.

Poli G \& Fauci AS (1992) The effect of cytokines and pharmacologic agents on chronic HIV infection. AIDS Research on Human Retroviruses 8, 191-197.

Poli G, Kinter AL, Justement JS, Bressler P, Kehrl J \& Fauci AS (1992) Retinoic acid mimics transforming growth factor $\beta$ in the regulation of human immunodeficiency virus expression in 
monocytic cells. Proceedings of the National Academy of Sciences of the USA 89, 2689-2693.

Rahmathullah L, Underwood BA, Thulasiraj RD, Milton RC, Ramaswamy K, Rahmathullah R \& Babu G (1990) Reduced mortality among children in Southern India receiving a small weekly dose of vitamin A. New England Journal of Medicine 323, 929-935.

Rodriguez-Amaya DB (1997) Carotenoids and Food Preparation: the Retention of Provitamin A Carotenoids in Prepared, Processed, and Stored Foods, Washington, DC: OMNI Project.

Rosales FJ, Kjolhede C \& Goodman S (1996) Efficacy of a single oral dose of 200,000 IU of oil-soluble vitamin A in measlesassociated morbidity. American Joumal of Epidemiology 143, 413-422.

Ross DA (1995) Vitamin A plus measles vaccination: the downside of convenience? Lancet 345, 1317-1318.

Sazawal S, Black RE, Bhan MK, Jalla S, Bhandari N, Sinha A \& Mahjumdar S (1996) Zinc supplementation reduces the incidence of persistent diarrhea and dysentery among low socioeconomic children in India. Journal of Nutrition 126, 443450.

Semba RD, Graham NMH, Caiaffa WT, Margolick JB, Clement L \& Vlahov D (1993) Increased mortality associated with vitamin A deficiency during human immunodeficiency virus type 1 infection. Archives of Internal Medicine 153, 2149-2154.

Semba RD, Miotti PG, Chiphangwi JD, Saah AJ, Canner JK, Dallabetta GA \& Hoover DR (1994) Maternal vitamin A deficiency and mother-to-child transmission of HIV-1. Lancet 343, 1593-1597.

Semba RD, Munasir Z, Beeler J, Akib A, Muhilal, Audet S \& Sommer A (1995) Reduced seroconversion to measles in infants given vitamin A with measles vaccination. Lancet $\mathbf{3 4 5}$, $1330-1332$.

Solon FS, Popkin BM, Fernandez TL \& Latham MC (1978) Vitamin A deficiency in the Philippines: a study of xerophthalmia in Cebu. American Joumal of Clinical Nutrition 31, 360368.

Sommer A (1982) Nutritional Blindness: Xerophthalmia and Keratomalacia. New York: Oxford University Press.

Sommer A, Tarwotjo I, Djunaedi E, West KP Jr, Loeden AA, Tilden R, Mele L \& the Aceh Study Group (1986) Impact of vitamin A supplementation on childhood mortality: a randomised controlled community trial. Lancet $\mathbf{i}, 1169-1173$.

Sommer A \& West KP Jr (editors) (1996) In Vitamin A Deficiency: Health, Survival, and Vision. New York: Oxford University Press.

Stoltzfus RJ, Hakimi M, Miller KW, Rasmussen KM, Dawiesah S, Habicht J-P \& Dibley MJ (1993) High dose vitamin A supplementation of breast-feeding Indonesian mothers: effects on the vitamin A status of mother and infant. Journal of Nutrition 123, 666-675.
Tang AM, Graham NMH, Kirby AJ, McCall LD, Willett WC \& Saah AJ (1993) Dietary micronutrient intake and risk of progression to acquired immunodeficiency syndrome (AIDS) in human immunodeficiency virus type 1 (HIV-1)-infected homosexual men. American Journal of Epidemiology 138, 937-951.

Tang AM, Graham NMH, Semba RD \& Saah AJ (1997) Association betwen serum vitamin A and E levels and HIV-1 disease progression. AIDS 11, 613-620.

Turpin JA, Vargo M \& Meltzer MS (1992) Enhanced HIV-1 replication in retinoid-treated monocytes. Retinoid effects mediated through mechanisms related to cell differentiation and to direct transcriptional action on viral gene expression. Journal of Immunology 148, 2539-2546.

Upadhyay MP, Gurung BJ, Pillai KK \& Nepal BP (1985) Xerophthalmia among Nepalese children. American Journal of Epidemiology 121, 71-77.

Vijayaraghavan K, Radhaiah G, Prakasam BS, Sarma KVR \& Reddy V (1990) Effect of massive dose vitamin A on morbidity and mortality in Indian children. Lancet 336, 1342-1345.

Vitamin A and Pneumonia Working Group (1995) Potential interventions for the prevention of childhood pneumonia in developing countries: a meta-analysis of data from field trials to assess the impact of vitamin A supplementation on pneumonia morbidity and mortality. Bulletin of the World Health Organization 73, 609-619.

Ward BJ, Humphrey JH, Clement L \& Chaisson RE (1993) Vitamin A status in HIV infection. Nutrition Research 13, 157166.

Ward BJ \& Semba RD (1994) Vitamin A and HIV infection. In Nutrition and AIDS, pp. 141-166 [RR Watson, editor]. Boca Raton, FL: CRC Press.

West KP Jr, Katz J, Shrestha SR, LeClerq SC, Khatry SK, Pradhan EK, Adhikari R, Wu LS-F, Pokhrel RP \& Sommer A (1995) Mortality of infants $<6$ mo of age supplemented with vitamin A: a randomized, double-masked trial in Nepal. American Joumal of Clinical Nutrition 62, 143-148.

West KP Jr, Khatry SK, LeClerq SC, Adhikari R, See L, Katz J, Shrestha SR, Pradhan EK, Pokhrel RP \& Sommer A (1992) Tolerance of young infants to a single, large dose of vitamin A: a randomized, community trial in Nepal. Bulletin of the World Health Organization 70, 733-739.

West KP, Pokhrel RP, Katz J, Le Clerq SC, Khatry SK, Shrestha SR, Pradhan EK, Tielsch JM, Pandey MR \& Sommer A (1991) Efficacy of vitamin $A$ in reducing preschool child mortality in Nepal. Lancet 338, 67-71.

World Bank (1993) Investing in Health: The 1993 World Development Report. New York: Oxford University Press \& World Bank.

Yamamoto N, Harada S \& Nakashima H (1986) Substances affecting the infection and replication of human immunodeficiency virus (HIV). AIDS Research 2, Suppl. 1, S183-S189. 